\title{
The indaba declaration on food, nutrition, health and sustainable development
}

We from Africa, Asia, the Middle East, Latin America, Europe and North America, from government, industry, academia, charitable foundations, the health professions, and civil society, met as participants at the Implementation Conference organised by the Stakeholders' Forum for Our Common Future at the Indaba Centre, Sandton, South Africa, on the occasion of the World Summit on Sustainable Development in August 2002, declare and agree as follows.

In the Zulu language 'Indaba' means 'meeting together for a common purpose, to agree on action'. This is what we have done.

\section{The basics}

- Good health is a vital input to, and outcome of, sustainable development.

- Good health can be achieved only by addressing the underlying and basic causes of disease.

- The modifiable causes of health and disease are environmental.

- The nature and quality of food systems, and therefore of diet and nutrition, are fundamental determinants of human health and welfare, and that of the whole living and natural world.

\section{The issues}

Levels of environmentally determined diseases now amount to a global emergency, projected to become an irretrievable catastrophe.

The triple burden now borne by almost all middle- and low-income countries of: nutritional deficiencies, infectious diseases including HIV-AIDS, malaria and tuberculosis, and chronic diseases including cancer, heart disease and stroke, and often also of violence, is too heavy for any country to bear. In particular:

- Nutritional deficiencies and infectious diseases persist throughout the world.

- The effect of HIV-AIDS most of all in sub-Saharan Africa is catastrophic.

- Rates of many chronic diseases in middle- and lowincome countries are soaring.

- Cancer, heart disease and stroke are now the leading causes of premature death in almost all countries.

- Projections show a vast increase of chronic diseases, including obesity and diabetes in early life

- On a population basis, no country has the resources to treat chronic diseases.

- In general, current political and economic policies are increasing the global burden of disease.

\section{The causes}

A key immediate cause of all types of disease is grossly inadequate or inappropriate food and nutrition, including food insecurity, and for chronic diseases, use of tobacco and physical inactivity.

The underlying and basic causes of disease are social, economic and political. These include inadequate maternal and childcare, poor breast-feeding and weaning practices, insufficient health services; lack of education and information; inadequate sanitation, polluted water; poverty, inequality, injustice; personal, communal and national debt; unemployment, dangerous environments, precipitate urbanisation; unsustainable agriculture, land degradation; poor governance, expropriation, dislocation; the effects of colonialism, unfair terms of trade, subsidy of industry in high-income countries; destruction of indigenous and traditional food systems and culture; commodity speculation, unregulated markets, aggressive promotion of degraded, cheapened and energy-dense food and drink; the use of food aid and trade as an instrument of power; and persecution, terror and war.

\section{The approaches}

On a population basis, the only rational approach to all types of disease is prevention, and most of all the protection and creation of healthy environments, at household, community, municipal, state, national and global levels.

This approach must include the protection, development and creation of food systems that are appropriate, sustainable and dynamic, designed to preserve, strengthen and improve the human and also the living and natural world.

Information and education, including product labelling, are necessary but insufficient in prevention of disease and promotion of health, and by themselves do not work.

Successful and accepted public policies for example concerning transport, energy, firearms, tobacco, alcohol 
and water, include legal, regulatory and fiscal instruments designed to balance the interests of civil society with those of industry and government. The protection and creation of healthy food systems, integral to healthy environments and to human health, also requires the use of law, regulation, and pricing policy, as well as integrated multisectoral and multi-disciplinary actions with all stakeholders as partners.

\section{The achievements}

We acknowledge Principle One of the Rio Declaration on Environment and Development, which states human beings are at the centre of concerns for sustainable development. They are entitled to a healthy and productive life in harmony with nature'.

We note that the agenda of the World Summit on Sustainable Development rightly indicates that the control and prevention of all types of disease requires protection or change of environments to keep or make them healthy.

We accept existing frameworks of understanding of causation of health and disease, such as the UNICEF conceptual framework on malnutrition.

We endorse the policy on infant and young child nutrition now adopted by WHO and all relevant UN agencies, which includes the evidence-based agreement that the optimal duration of exclusive breast-feeding is six months.

We support the WHO Global Strategy on Diet, Physical Activity and Health, and the draft WHO/FAO report on which it is based. We endorse the first principles of the strategy, including stakeholder involvement, advocacy designed to make policy action plans succeed, a life-course approach to health, and emphasis on middleand low-income countries. We support many of the actions recommended in the draft report, in particular those that address the underlying and basic causes of disease.

We applaud the decision of the International Union of Nutritional Sciences to set up a special task force on 'eco-nutrition', meaning that nutrition must be concerned with planetary as well as personal and population health, and the decision of the organisers of the next World Congress on Nutrition to be held in Durban in 2005, to include nutrition and the environment as a key theme.

\section{The actions}

Many actions can now be taken that will have the effect of controlling and preventing all types of disease.

We, the signatories to this document, have the capacity to act as follows. Inspired by the Indaba process, we pledge:

- To support the basic philosophy of the WHO global strategy and the joint FAO/WHO consultation document on diet, nutrition and the prevention of chronic diseases, and to advocate its implementation at all levels including civil society, national governments, and international bodies.

- To disseminate this Declaration on relevant websites and journals, in meetings with relevant UN executives and national governments, professional bodies and NGOs, and to recommend that its themes and conclusions be given high priority at further international meetings involving the UN system and nation states.

- To use our professional and national networks, and the Stakeholder Forum network, to advocate and disseminate the WHO global food and nutrition strategy.

- To advocate that the strategy be amplified, become holistic, and so include all forms of malnutrition. It therefore should also include nutritional deficiency and infectious diseases as well as chronic diseases, and emphasise the underlying and fundamental causes of health and disease, so as to be fully relevant in middleand low-income countries, where nutritional deficiency and chronic diseases including obesity co-exist at all levels, even in the same household.

Signed:

Benjamin Alli

Gordon Baker

Barrett Brown

Dolline Busalo

Geoffrey Cannon

Larry Casazza

MK Cham

Yvonne Clemen

Elizabeth Danielyan

Farida Dollie

Timothy Evans

Lars Friberg

Christiaan Geldenhuys
International Labour Office

Stakeholder Forum

Carebridge

Helpage

World Health Policy Forum

World Vision

World Health Organization

Wellness InfoNet

Women for Health

Human Rights

Rockefeller Foundation

Stakeholder Forum

Sweetspot
Switzerland

UK

UK

Kenya

Brazil

USA

Switzerland

South Africa

Armenia

South Africa

USA

Sweden

South Africa 
John Goss

Minu Hemmati

Johann Jerling

George Kararach

Nicholas King

George de Klerk

Estelle de Klerk

Salome Kruger

Anand Kumar

Lam Kok Liang

Patrick Maitland

Philip Makhumula-Nkhoma

Rita Njan

Paul Rheeder

David Sanders

Louise Sarch

Andrew Seiter

Tanay Sidki Uyar

Marthinette Slabber

Alyson Slater

Louise Smith

Peter Smith

Nelia Steyn

Liz Thebe

Pamela Thole

Anne Till

Jantjie Tumi

Hester H Vorster

Jeroen Warner

Sandton, South Africa

August 2002
Cinnabar Global Circle

South Africa

Stakeholder Forum

Nutrition Society

UNICEF

BioNet

Department of Health

Department of Health

Potchefstroom University

Astra Zeneca

Consultant

Agriculturalist

University of Malawi

World Health Organization

University of Pretoria

University of the Western Cape

National Heart Forum

Novartis

Kados

University of the Free State

Global Reprinting Initiative

Country Women of the World

Slow Food Movement

Medical Research Council

Massive Effort

Zamseed

Anne Till Associates

Uthingo Management

Potchefstroom University

Wageningen University
London

South Africa

Zimbabwe

UK

South Africa

South Africa

South Africa

India

Malaysia

Jamaica

Malawi

Kenya

South Africa

South Africa

UK

Switzerland

Turkey

South Africa

USA

South Africa

South Africa

South Africa

South Africa

Zambia

South Africa

South Africa

South Africa

Netherlands

\section{Notes}

\section{Stakebolders}

The stakeholders in this process include civil society, the health professions, charitable foundations, academia, industry, government, and their representative and accountable organisations.

\section{Food systems}

This concept is holistic. Food systems include the whole process of production, manufacture, distribution, sale and consumption of food and drink, and also take account of climate, terrain, history, tradition and culture. Integrated and indefinitely sustainable food systems are the keystone of human health, and also a foundation for the independence of nations and the health of the whole living and natural world.

\section{Chronic diseases}

These are non-communicable diseases, either debilitating, disabling, or deadly. They affect all systems of the body. They include oral diseases including dental caries, gut disorders and diseases, obesity, diabetes, cardiovascular diseases (including high blood pressure, stroke and coronary heart disease), osteoporosis, and cancer. Different chronic diseases have common causes. Chronic diseases are now the chief causes of premature disability and death in almost all countries in the world. The chief immediate causes of chronic diseases are use of tobacco, grossly imbalanced food and nutrition and physical inactivity. 